\title{
La protección de la calidad de las aguas
}

\author{
María del Carmen Ortiz de Tena \\ Prof. Titular de Derecho Administrativo. \\ Universidad de Sevilla
}

\section{EL INTERÉS GRECIENTE POR LA CALIDAD DE LAS AGUAS ${ }^{1}$}

En los últimos años, se ha desarrollado en nuestro país un interés creciente por el tema de la calidad de las aguas, que tiene su reflejo en el seno del ordenamiento jurídico. En el ámbito del Derecho de aguas, por supuesto. Como ya indicó en su día el Prof. EMBID IRUJO, A. ${ }^{2}$, el actual ordenamiento jurídico de las aguas coloca a la cuestión de la calidad entre uno de los puntos cimeros de sus preocupaciones. La atención preferente por la calidad del agua $^{3}$, recogida en la Ley de Aguas de 1985, se va a intensificar sobre todo a partir de la reforma al texto legal con el establecimiento de una regulación más rigurosa de los vertidos, la incorporación introducida por la Ley 46/1999, de 13 de diciembre del denominado "caudal ecológico", las reformas encami-

\footnotetext{
${ }^{1}$ El presente trabajo se realiza en el seno del grupo de investigación "Derecho público, responsabilidad, control y ordenación del territorio" (P06-SEJ-01754); constituye una versión revisada de un estudio incluido en el Vol. col. Comentarios a la Ley de Gestión Integrada de la Calidad ambiental, bajo el título "Calidad del Medio hídrico", Ed. Aranzadi. Pamplona, 2008.

${ }^{2}$ Cfr. "Principios generales sobre el ordenamiento jurídico-administrativo de la calidad de las aguas", en Vol. col. dirigido por este mismo autor, La calidad de las aguas. Civitas, Madrid, 1994, p. 27.

${ }^{3}$ Además antes del citado, en relación con la calidad de las aguas pueden verse, entre otros, los siguientes trabajos: DELGADO PIQUERAS, F. Derecho de aguas y medio ambiente. El paradigma de la protección de los humedales. Tecnos, Madrid, 1992; y "El proceso de aplicación de la Ley de Aguas de 1985 y las nuevas exigencias de protección del dominio hidráulico que plantea la Directiva Marco del Agua", en Derecho de Aguas, IEA, Murcia, 2006, pp. 839 y ss. ; MARTÍN MATEO, R. "Evolución del régimen de tutela ambiental de las aguas continentales", en EMBID IRUJO, A. (Dir). El Derecho de Aguas en Iberoamérica y España: cambio y modernización en el inicio del tercer milenio. Civitas, Madrid, 2002. Tomo I, pp. 171-187; MARTÍN-RETORTILLO BAQUER, S. Derecho de Aguas. Civitas, Madrid, 1997, pp. 307-370; SÁNCHEZ MORÓN, M.: "Aspectos ambientales de la modificación de la Ley de Aguas", en EMBID IRUJO, A. (Dir). La reforma de la Ley de Aguas (Ley 46/1999, de 13 de diciembre). Civitas, Madrid, 2000, pp. 87-111.
} 
nadas a incentivar un aprovechamiento más eficiente del agua mediante la figura de los contratos de cesión de derechos al uso del agua, etc, y va a llegar hasta el núcleo mismo de la Planificación hidrológica que, como es sabido, constituye la columna vertebral de nuestro Derecho de aguas.

En efecto, es cierto que los planes hidrológicos no fueron nunca concebidos por el legislador de 1985 como meros instrumentos al servicio de la satisfacción de las demandas de agua. Pero ahora hay que reconocer que el enfoque ambiental se ha intensificado. Lo que entonces estaba en ciernes, se ha ido desarrollando paulatinamente pasando a ocupar un primer plano. Se puede decir así que en la actualidad la preocupación por la calidad de las aguas se ha convertido en el primer y principal objetivo de los planes hidrológicos. No en vano, el Art. 40 del Texto Refundido de la Ley de Aguas -en adelante TRLA- coloca en primer lugar, entre los objetivos generales de la planificación hidrológica, "conseguir el buen estado y la protección del dominio público hidráulico y de las aguas"”.

Y no son sólo los objetivos, sino que la dimensión ambiental de los planes hidrológicos se infiere también del análisis de sus propios contenidos ${ }^{5}$, algunos de ellos introducidos en nuestro ordenamiento a raíz de la aprobación de la Directiva Marco de Aguas (DMA) ${ }^{6}$. La incidencia de esta última normativa europea en nuestro ordenamiento de aguas ha sido notable. Por lo que respecta a la planificación hidrológica, la repercusión se produce en un triple sentido $^{7}$ : En primer lugar, en cuanto al ámbito territorial de los planes hidrológicos, que se amplía con la introducción del concepto de "demarcación hidrográfica" ${ }^{\prime}$; en segundo término, por la introducción de nuevos contenidos

\footnotetext{
${ }^{4}$ Aprobado por Real Decreto-Legislativo 1/2001, de 20 de julio.

${ }^{5}$ Vid. en este sentido PALLARÉS SERRANO, A. La planificación hidrológica de cuenca como instrumento de ordenación ambiental sobre el territorio. Tirant lo blanch. Valencia, 2007. A través de esta obra la autora trata de analizar las deficiencias que presenta actualmente el sistema de coordinación entre los planes administrativos que tienen por objeto la protección del medio físico y apuesta por la planificación hidrológica de cuenca como un instrumento esencial para lograr la integración y coordinación de las diferentes planificaciones ambientales.

${ }^{6}$ Directiva 2000/60, del Parlamento Europeo y del Consejo, de 23 de octubre -en adelante DMApor la que se establece un marco comunitario de actuación en el ámbito de la política de aguas.

${ }^{7}$ Vid. al respecto nuestro trabajo sobre "La revisión de los planes hidrológicos de cuenca en el nuevo marco jurídico del Derecho de Aguas”, publicado en el Vol. Col. Derecho de Aguas. IEA. Murcia, 2006, pp. 767-789.

${ }^{8}$ Este nuevo ámbito, que no rompe el principio de unidad de cuenca hidrográfica, incluye no sólo a las aguas continentales sino también a las "aguas costeras" y a las "aguas de transición".
} 
a través de los denominados "programas de medidas" (los "programas de medidas" se anexionan a los contenidos clásicos de nuestros planes hidrológicos, constituyen la figura estrella introducida por la DMA y su contenido puede ser diverso tanto desde el punto de vista material como de su naturaleza jurídica); y finalmente, por lo que respecta a los procedimientos de revisión de los planes hidrológicos, estableciendo mayores exigencias en orden al suministro de información y en relación a la participación pública en el proceso de elaboración, revisión y actualización de los planes hidrológicos. En definitiva, podemos afirmar que en la DMA los planes hidrológicos se conciben como el gran instrumento al servicio del cumplimiento de los objetivos medioambientales establecidos por la propia Directiva.

También ha estado y está presente la atención hacia los temas de calidad del agua en toda la normativa medioambiental. No podía ser de otro modo. El agua, en cuanto recurso natural básico para la vida del hombre, forma parte imprescindible de ese medio ambiente adecuado al que todos tenemos derecho. Los recursos hidráulicos constituyen hoy en día un bien medioambiental de primer orden ${ }^{9}$.

En el seno de la Comunidad Autónoma de Andalucía se aprobó la Ley 7/2007, de 9 de julio, de Gestión Integrada de la Calidad Ambiental -en adelante LGICA-, que dedica un capítulo de su Título IV (sobre Calidad Ambiental), a lo que denomina la "Calidad del medio hídrico".

La LGICA trata de ofrecer una regulación que busca, en aras de un uso sostenible del recurso, un punto de equilibrio entre la protección del medio ambiente y el desarrollo económico. La protección de la calidad del medio hídrico se integra así como contenido propio y parte integrante de la protección de la calidad ambiental.

\footnotetext{
${ }^{9}$ Aunque la delimitación y extensión del concepto de medio ambiente ha sido una cuestión debatida en la doctrina y la jurisprudencia, no ofrece duda en cambio la inclusión del agua como parte inescindible de aquél. El agua es un bien medioambiental, imprescindible para la vida de los animales y de las plantas, sustrato físico o elemento natural en el que viven, crecen y mueren numerosas especies del mundo animal o vegetal. Por ello, los ecosistemas vinculados con el agua tienen una extraordinaria importancia para el medioambiente, debiendo ser objeto de una especial protección. Ello se manifiesta, por ejemplo, en la existencia de los denominados "caudales medioambientales", concebidos en nuestro ordenamiento como una restricción, o limitación que se impone con carácter general a los sistemas de explotación (vid. Art. 59.7 TRLA y Art. 26 de la Ley 11/2005 del Plan Hidrológico Nacional).
} 


\section{LA AMPLIACIÓN DEL OBJETO DE PROTECGIÓN}

Llama la atención, en primer lugar, el objeto sobre el que recae la protección que ofrece la LGICA, que se ciñe no sólo a las aguas continentales, sino también a las litorales. Y no sólo al dominio hídrico líquido, sino también al dominio "sólido".

La Ley andaluza establece así una regulación común de la protección del litoral y de la protección de las aguas continentales ${ }^{10}$. Su Art. 78, al definir su ámbito de aplicación, ordena que las disposiciones del Capítulo III se aplicarán a "las aguas continentales y litorales y al resto del dominio público-hidráulico ${ }^{11}$ y marítimo-terrestre, cuya competencia corresponda a la Comunidad Autónoma de Andalucía y sin perjuicio de lo dispuesto en la normativa básica en materia de aguas y costas”. Resulta además expresiva la misma rúbrica del citado Capítulo que incorpora la expresión "calidad del medio hídrico"12 en lugar de otra, más común y arraigada en nuestra legislación de aguas, la de "calidad de las aguas"13, que quizás quiera reflejar esa concepción global y omnicomprensiva de la acción protectora que persigue la Ley. Se produce así una ampliación de miras por parte del legislador andaluz que se sitúa en la misma línea establecida por la $\mathrm{DMA}^{14}$.

\footnotetext{
${ }^{10}$ Aunque la regulación es conjunta, el contenido sustantivo del Capítulo III tiene como patrón de referencia el TRLA.

${ }^{11}$ De acuerdo con el Art. 2 del TRLA, éste queda integrado por: los cauces de corrientes naturales, continuas o discontinuas -salvo los cauces por los que ocasionalmente discurran aguas pluviales en el sentido del artículo 5.1 del TRLA-; los lechos de los lagos y lagunas y los de los embalses superficiales en cauces públicos -salvo las charcas situadas en predios de propiedad privada, en virtud de lo establecido en el Art. 10 del TRLA- ; y los acuíferos, a los efectos de los actos de disposición o de afección de los recursos hidráulicos.
}

${ }^{12} \mathrm{El}$ "medio hídrico" es un concepto propio del Derecho ambiental, y expresión también próxima a la de "ecosistemas acuáticos", en la que destaca la presencia de elementos interrelacionados (agua, tierra, aire, personas, animales, plantas). El diccionario de la Real Academia Española de la Lengua define el concepto de "medio", en una de sus acepciones, como el "elemento en el que vive o se mueve una persona, animal o cosa" y, en otra, como "el conjunto de circunstancias físicas que rodean a los seres vivos".

${ }^{13}$ A pesar de ello, a lo largo del texto de la ley andaluza se encuentran alusiones al término "calidad de las aguas".

14 Tal como indica su EM, en cuanto a la calidad de las aguas, la LGICA desarrolla lo dispuesto en la DMA. 
Las aguas incluidas en el ámbito de aplicación de la LGICA se definen en el Art. $79^{15}$ :

1. Aguas continentales: Todas las aguas quietas o corrientes en la superficie del suelo y todas las aguas subterráneas ${ }^{16}$ situadas hacia tierra desde la línea que sirve de base para medir la anchura de las aguas territoriales.

2. Aguas litorales: Las aguas de transición, las aguas costeras y las aguas territoriales.

3. Aguas costeras: Las aguas superficiales situadas hacia tierra desde una línea cuya totalidad de puntos se encuentra a una distancia de una milla acuática mar adentro desde el punto más próximo de la línea base que sirve para medir la anchura de las aguas territoriales y que se extienden, en su caso, hasta el límite exterior de las aguas de transición.

4. Aguas de transición: Masas de aguas superficiales próximas a la desembocadura de los ríos que son parcialmente salinas como consecuencia de su proximidad a las aguas costeras, pero que reciben influencia de flujos de agua dulce.

Las aguas continentales, las aguas de transición y las costeras -de acuerdo con lo dispuesto en la DMA- habían quedado incluidas en el ámbito de las denominadas "demarcaciones hidrográficas"17. Ahora, la LGICA da un paso más y extiende

\footnotetext{
${ }^{15}$ Algunas de estas definiciones estaban contenidas en la DMA (aguas continentales, aguas costeras y aguas de transición) y fueron incluidas en el TRLA tras la reforma operada en él por el Art. 129 de la Ley 62/2003, de 30 de diciembre.

${ }^{16}$ En relación a las aguas subterráneas téngase en cuenta la Directiva 2006/118/CE, de 12 de diciembre, de Protección de las aguas subterráneas contra la contaminación y el deterioro, que establece medidas específicas para prevenir y controlar la contaminación de las aguas subterráneas. Dicha Directiva completa las disposiciones contenidas en la DMA destinadas a prevenir o limitar las entradas de contaminantes en las aguas subterráneas y evitar el deterioro del estado de todas las masas de agua subterránea.

17 Que, como ya hemos señalado, había sido designado por aquella como principal unidad a efectos de gestión de las cuencas hidrográficas. Su Art. 2.15 las definía como "la zona marina y terrestre compuesta por una o varias cuencas hidrográficas vecinas y las aguas subterráneas y costeras asociadas...".
} 
también sus efectos a las aguas territoriales ${ }^{18}$ (que se integran dentro de las aguas litorales) y al resto del dominio público hidráulico y marítimo-terrestre.

Desde el punto de vista de su naturaleza jurídica y, a pesar de la expresión "resto del dominio público...", entendemos que los bienes objeto de protección no son sólo los de naturaleza demanial -la mayoría- sino todos los recursos naturales integrados en dicho ámbito ${ }^{19}$, incluyendo también a las titularidades privadas sobre los recursos hidráulicos subsistentes tras la demanialización operada por la Ley de Aguas de $1985^{20}$.

Para todas estas aguas (y para los ecosistemas asociados a ellas), la Ley andaluza pretende alcanzar un alto nivel de protección de la calidad; es decir, no sólo persigue evitar o limitar al menos su deterioro o contaminación, sino también, a través de una acción positiva, mejorar la calidad del medio hídrico. Se conecta así la norma con el contenido del Art. 45.2 de la CE, cuando ordena que los poderes públicos "velarán por la utilización racional de los recursos naturales, con el fin de proteger y mejorar la calidad de vida...”.

Este marco jurídico de protección de las aguas debe permitir, tal como reza en el Art. 80 de la LGICA ${ }^{21}$ : prevenir el deterioro, proteger y mejorar el es-

\footnotetext{
${ }^{18}$ Es decir, aquella porción de aguas pertenecientes al mar territorial (12 millas náuticas) a partir del límite establecido para las aguas costeras (una milla náutica mar adentro desde el punto más próximo de la línea de base que sirve para medir la anchura de las aguas territoriales).

${ }^{19} \mathrm{Tal}$ interpretación entendemos que es acorde con la DMA, que no distingue el régimen jurídico de las aguas cuando establece sus normas de protección. Dice así su Art. 1: "El objeto de la presente Directiva es establecer un marco para la protección de las aguas superficiales, las aguas de transición, las aguas costeras y las aguas subterráneas".
}

${ }^{20}$ Las salvedades expresamente establecidas por esta Ley, que no constituyen dominio público, son las siguientes: las aguas subterráneas no renovables o fósiles (Art. 2.1); los cauces de dominio privado (Art. 5); las charcas situadas en predios de propiedad privada (Art. 10); los lagos y lagunas sobre los que existan inscripciones expresas en el Registro de la Propiedad (Disposición Adic. $1^{\text {a }}$ ); y los derechos sobre aguas privadas procedentes de manantiales, pozos o galerías derivados de la Ley de 13 de junio de 1879 y que fueron inscritos en el Catálogo de Aguas de la cuenca (Disp. Trans. $2^{\mathrm{a}}$ y $3^{\mathrm{a}}$ ).

Obsérvese que el Art. 1.2 del TRLA señala como uno de los objetivos de la Ley el establecimiento de las normas básicas de protección de las aguas continentales, costeras y de transición, "sin perjuicio de su calificación jurídica y de la legislación específica que les sea de aplicación" (el entrecomillado es nuestro).

${ }^{21}$ Que desarrolla en este punto al Art. 1 de la DMA. 
tado de los ecosistemas acuáticos, y de los terrestres y humedales asociados a ellos; proteger y mejorar el medio hídrico para alcanzar en él concentraciones cercanas a los niveles de fondo, por lo que se refiere a sustancias de origen natural, y próximas a cero, por lo que respecta a las sustancias sintéticas, mediante la reducción progresiva de la contaminación procedente de sustancias prioritarias y la eliminación y supresión gradual de los vertidos, las emisiones y las pérdidas de sustancias peligrosas prioritarias; garantizar la reducción progresiva de la contaminación de los acuíferos, así como de las aguas o capas subterráneas y evitar su contaminación adicional; alcanzar los objetivos fijados en acuerdos internacionales para prevenir y eliminar la contaminación del medio ambiente marino; evitar la acumulación de compuestos tóxicos o peligrosos en el subsuelo que pueda causar la degradación del dominio público hidráulico y marítimo terrestres; y finalmente, alcanzar los objetivos medioambientales establecidos en la legislación vigente, y, en particular, el buen estado de las aguas.

\section{LAS COMPETENCIAS DE LA COMUNIDAD AUTÓNOMA DE ANDALUCÍA SOBRE LA PROTECGIÓN DE LA CALIDAD DEL MEDIO HÍDRICO}

Las competencias de la Comunidad Autónoma de Andalucía sobre la protección de la calidad del medio hídrico vienen determinadas, por un lado, por el esquema de reparto competencial entre el Estado y las CCAA en materia de medio ambiente ${ }^{22}$, y por otro, por la distribución competencial existente en materia de aguas ${ }^{23}$. A ello habrá que añadir la incidencia de otros títulos competenciales conexos que corresponden a las administraciones autonómicas y locales.

\footnotetext{
22 Como ya hemos señalado, la protección del medio hídrico puede considerarse como parte integrante de la protección ambiental. La EM de la LGICA señala que "la presente Ley encuentra su principal fundamento competencial en el Art. 57 del Estatuto de Autonomía que se la atribuye a nuestra Comunidad Autónoma, en materia de medio ambiente, espacios protegidos y sostenibilidad, y sus principios orientadores responden a los objetivos marcados en su Título VII relativo al medio ambiente".

En relación a las competencias medioambientales asumidas por la Comunidad Autónoma de Andalucía puede consultarse el trabajo del Prof. JORDANO FRAGA, J. "Medio Ambiente y el nuevo Estatuto de Autonomía de Andalucía. Una visión preliminar" en Revista Andaluza de Administración Pública, 65/2007, pp. 35-55.

23 Sobre el tema vid. CARO-PATÓN CARMONA, I.: "Problemas competenciales de la protección medioambiental del agua” en Derecho de Aguas, IEA, Murcia, 2006, pp. 889-907.
} 
Veámoslo paso a paso: Como es sabido, en materia de medio ambiente, al Estado le corresponde la legislación básica, y a las CCAA la legislación de desarrollo y las normas adicionales de protección. Dicho reparto, por lo que respecta a la protección del medio hídrico, va a quedar modulado por la distribución de competencias que opera en materia de aguas, en donde el criterio territorial de unidad de la cuenca hidrográfica se convierte en regla decisiva en orden a determinar las competencias tanto del Estado como de las Comunidades Autónomas que han asumido competencias sobre recursos y aprovechamientos hidráulicos $^{24}$. De la aplicación de dicho criterio resultan dos regímenes competenciales diferentes, que afectan también a la protección de la calidad de las aguas: uno, el establecido para las cuencas intercomunitarias y, otro, el previsto en las cuencas intracomunitarias. En Andalucía, esta dualidad de regímenes competenciales coexisten, aunque tras la reforma del Estatuto de Autonomía para Andalucía de 2007, tal duplicidad en la práctica queda muy diluida por la asunción de competencias autonómicas sobre la cuenca del río Guadalquivir ${ }^{25}$. Como es sabido, en el territorio andaluz se ubican cuencas hidrológicas de diferente carácter: las cuencas intracomunitarias andaluzas de la vertiente atlántica ${ }^{26}$, las cuencas intracomunitarias andaluzas de la vertiente mediterránea ${ }^{27}$, y principalmente la cuenca del río Guadalquivir, que tiene

\footnotetext{
${ }^{24}$ Sobre el criterio territorial de distribución de competencias en materia de aguas y su interpretación desde el principio de unidad de cuenca se ha escrito mucho. Por todos véase FANLO LORAS, A.: La unidad de gestión de las cuencas hidrográficas. IEA, Murcia, 2007.
}

25 Vid. al respecto el excelente trabajo del Prof. LÓPEZ-MENUDO, F. "Competencias en materia de aguas. En especial, la cuenca hidrográfica del Guadalquivir” en Comentarios al Estatuto de Autonomía para Andalucía. Civitas. Madrid, 2008, p. 457 y ss; y FANLO LORAS, A. "La atribución de la Cuenca del Guadalquivir a la Comunidad Autónoma de Andalucía", en La unidad de gestión..., ob. cit. p. 293 y ss.

${ }^{26}$ Las que vierten al Atlántico son: las de los ríos Guadalete y Barbate en Cádiz (antes gestionadas por la Confederación Hidrográfica del Guadalquivir) y las de los ríos Tinto, Odiel, Piedras y Chanza en Huelva (gestionadas anteriormente por la Confederación Hidrográfica del Guadiana). Todas ellas fueron traspasadas a la Comunidad Autónoma de Andalucía mediante el Real Decreto $1560 / 2005$, de 23 de diciembre.

${ }^{27}$ Son las que vierten al Mediterráneo y se sitúan entre el límite de los términos municipales de Tarifa y Algeciras hasta la cuenca y desembocadura del río Almanzora, incluyendo también la cuenca endorreica de Zafarraya; cuya gestión correspondía a la Confederación Hidrográfica del Sur, y que fueron traspasadas a la Comunidad Autónoma de Andalucía mediante Real Decreto 2130/2004, de 29 de octubre. 
carácter intercomunitario ${ }^{28}$, además de las cuencas intercomunitarias del Guadiana (que discurre parcialmente por la provincia de Huelva) y del Segura (que cursa por la provincia de Jaén). Aunque a la fecha en que redactamos estas líneas no ha recaído aún la Sentencia del Tribunal Constitucional que resuelva el recurso de inconstitucionalidad interpuesto por la Comunidad de Extremadura contra el Art. 51 del Estatuto andaluz, que como es sabido asume competencias sobre la cuenca del río Guadalquivir, es ya una realidad el traspaso a la Junta de Andalucía de tales competencias operado mediante Real Decreto 166/2008, de 17 de octubre, sobre traspaso de funciones y servicios de la Administración del Estado en materia de recursos y aprovechamientos hidráulicos correspondientes a las aguas de la cuenca del Guadalquivir que discurren íntegramente por el territorio de la comunidad autónoma andaluza.

Dentro de la protección de la calidad de las aguas merece mención especial la regulación de los vertidos, materia que, según ha declarado en diversas ocasiones el Tribunal Constitucional, tiene su encaje dentro de la competencia genérica sobre protección del medio ambiente ${ }^{29}$. Ello significa que, aun-

\footnotetext{
${ }^{28}$ La cuenca del río Guadalquivir, a pesar de estar situada casi al completo en territorio andaluz, tiene carácter intercomunitario y afecta también, aunque mínimamente, a las Comunidades Autónomas de Extremadura, Castilla-La Mancha y Murcia. Su gestión ha correspondido a la Confederación Hidrográfica del Guadalquivir, pero con fecha 12 de noviembre de 2007 se firmó un Acuerdo de la Comisión Bilateral de Cooperación Junta de Andalucía-Estado para su traspaso a la Comunidad Autónoma de Andalucía. Tal Acuerdo tiene su base en el Art. 51 del nuevo Estatuto de Andalucía de 2007, aprobado mediante Ley Orgánica 2/2007, de 19 de marzo, que asume competencias exclusivas sobre las aguas de dicha cuenca que transcurren por su territorio y no afecten a otra Comunidad Autónoma. Este precepto estatutario ha sido objeto de un recurso de inconstitucionalidad ante el TC $\left(\mathrm{n}^{\circ} 5120-2007\right)$, interpuesto por el Consejo de Gobierno de la Junta de Extremadura, admitido a trámite mediante Providencia de fecha 3 de julio de 2007, y, que aún está pendiente de resolver.

Sobre el modelo organizativo elegido por la Comunidad Autónoma Andaluza para la gestión de sus cuencas intracomunitarias puede consultarse el trabajo de HORGUÉ BAENA, C. Voz "Administración hídrica de Andalucía", publicado en Vol. col. dirigido por EMBID IRUJO, A.: Diccionario de Derecho de Aguas. Iustel, Madrid, 2007, pp. 55-65.

${ }^{29}$ Entre otras sentencias cabe citar la STC 227/1988, de 29 de noviembre, sobre la Ley de Aguas (Fdo. Jco. 26).

El nuevo Estatuto de Andalucía de 2007, en su Art. 57.3, atribuye a la Comunidad Autónoma la competencia compartida en relación con "la regulación y la gestión de los vertidos efectuados en las aguas interiores de la Comunidad Autónoma, así como de los efectuados a las aguas superficiales y subterráneas que no transcurren por otra Comunidad Autónoma (...) y la prevención, restauración y reparación de daños al medio ambiente, así como el correspondiente régimen sancionador. Asimismo, tiene competencias para el establecimiento de normas adicionales de protección".
} 
que la regulación estatal sobre los vertidos esté contenida principalmente en la legislación de aguas, a saber, TRLA (Título V, Capítulo II, Arts. 100 a 108), el esquema de distribución de competencias aplicable a los vertidos no es el que opera en relación a las aguas sino el previsto en materia de medio ambiente, por lo que dicha regulación tiene carácter de legislación básica, pudiendo ser desarrollada por las Comunidades Autónomas. Aun así, sobre este esquema de reparto habrá luego que sobreponer el criterio territorial de la cuenca hidrográfica, con el siguiente resultado: en las cuencas intercomunitarias corresponde a la Administración estatal, además de las competencias legislativas medioambientales, la tutela de la calidad de las aguas y el otorgamiento de las autorizaciones sobre el dominio público hidráulico, entre las que se incluyen las autorizaciones de vertido ${ }^{30}$; en las cuencas intracomunitarias, en cambio, las Comunidades Autónomas asumen, además de las competencias normativas (legislación de desarrollo más normas adicionales de protección), las competencias ejecutivas en relación a los vertidos, incluido el otorgamiento de las autorizaciones de vertido.

Junto a las competencias citadas, hay que tener presente otros títulos competenciales tanto estatales (protección del dominio público hidráulico, obras públicas de interés general...) como autonómicos (ordenación del territorio, sanidad, o pesca fluvial ${ }^{31}$...) que pueden incidir en la protección de la calidad de las aguas y en el régimen de los vertidos. Por último, están las

\footnotetext{
${ }^{30}$ Sin perjuicio de la intervención de las CCAA en los procedimientos de otorgamiento de dichas autorizaciones a través de la emisión de informes preceptivos en ejercicio de sus competencias sectoriales. En el caso de la cuenca del Guadalquivir, se han traspasado a la Junta de Andalucía, entre otras competencias, las autorizaciones relativas al uso y aprovechamiento del dominio público (Vid. Acuerdo Estado-Junta de Andalucía, de 12 de noviembre de 2007, para el traspaso de la cuenca del Guadalquivir y RD 1666/2008, de 17 de octubre, por el que se aprueba el Acuerdo de la Comisión Mixta Paritaria Gobierno-Junta de Andalucía adoptado por el Pleno en su reunión del día 20 de septiembre de 2008, que hace efectivo el Acuerdo antes citado. En su punto 2.c) se traspasa a la Junta las competencias sobre "la gestión y protección de los recursos hídricos, el otorgamiento de autorizaciones de vertido y de uso o aprovechamiento del dominio público hidráulico y sus zonas asociadas, la policía de aguas y cauces, la instrucción y resolución de procedimientos sancionadores en materia de aguas, así como las funciones de regulación y conducción de los recursos hídricos que tienen por objeto garantizar la disponibilidad y aprovechamiento de los mismos).

${ }^{31}$ El Estatuto de Andalucía de 2007 atribuye a la Comunidad Autónoma de Andalucía competencia exclusiva en materia de pesca marítima y recreativa en aguas interiores, marisqueo y acuicultura, almadraba y pesca con artes menores, el buceo profesional y la formación y las titulaciones en actividades de recreo (Art. 48.2).
} 
competencias de las Administraciones locales sobre saneamiento y depuración de aguas residuales. En definitiva, un abigarrado entrecruzamiento de títulos competenciales a distintos niveles que hace necesario establecer mecanismos de colaboración y coordinación interadministrativa para garantizar una protección efectiva del recurso.

La LGICA dedica su Art. 81 a enumerar las competencias sobre la protección de la calidad del medio hídrico, distinguiendo las que corresponden a la Comunidad autónoma (Art. 81.1) de las que se atribuyen a los municipios (Art. 81.2). La Ley andaluza no alude en ningún momento al carácter intercomunitario o intracomunitario de la cuenca en la que se ejerzan dichas competencias $^{32}$.

Entre las competencias de la Comunidad Autónoma (Consejería de Medio Ambiente), y sin perjuicio de lo dispuesto en la normativa básica en materia de aguas y $\operatorname{costas}^{33}$, se encuentran las siguientes funciones: el control de calidad de las aguas y el control de la contaminación, mediante la fijación de valores límite de vertido y el cumplimiento de los objetivos medioambientales; el establecimiento, aprobación y ejecución de los programas de seguimiento del estado de las aguas continentales y litorales de competencia de la Comunidad Autónoma; la clasificación del estado de las aguas y la elaboración de informes sobre el mismo; la operación y el mantenimiento de los dispositivos de vigilancia y control que posibiliten el seguimiento de la calidad de las aguas; la declaración de zonas sensibles y menos sensibles, de acuerdo con la normativa sobre tratamiento de aguas residuales urbanas; y de zonas vulnerables, de acuerdo con la normativa sobre contaminación por nitratos de origen agrario; el otorgamiento de las autorizaciones de vertido y el control y seguimiento de las condiciones establecidas en ellas; y la potestad sancionadora relativa a la protección de la calidad del medio hídrico en el ámbito de sus competencias.

En cuanto a las competencias municipales, según dispone el Art. 81.2 de la LGICA, a los municipios les corresponde, además de las que les reconoce la

\footnotetext{
32 Recordemos que de acuerdo con el Art. 58 del nuevo Estatuto de Autonomía de Andalucía de 2007, "la Comunidad Autónoma de Andalucía ostenta competencias exclusivas sobre las aguas de la Cuenca del Guadalquivir que transcurren por su territorio y no afectan a otra Comunidad Autónoma...”.

33 Según precisa el Art. 78 in fine de la LGICA.
} 
legislación de régimen local ${ }^{34}$, entre otras, las siguientes funciones: el control y seguimiento de vertidos a la red de saneamiento municipal, así como el establecimiento de medidas o programas de reducción de la presencia de sustancias peligrosas en dicha red; la elaboración de reglamentos u ordenanzas de vertidos al alcantarillado; y la potestad sancionadora referida a la protección de la calidad de las aguas en el ámbito de sus competencias.

Dos observaciones podemos hacer al respecto: primera, nos parece oportuna y correcta la atribución de la competencia sobre los vertidos indirectos a la red de saneamiento municipal a favor de los municipios, teniendo en cuenta que se trata de una cuestión que hasta ahora no ha estado regulada de forma clara por la legislación de aguas; segunda: la atribución de competencias del Art. 81.2 se hace en favor de los municipios, pero no se dice nada de las competencias que puedan ostentar otros entes locales distintos al municipio ${ }^{35}$ (pensamos, por ejemplo, en las Mancomunidades municipales, o en las Áreas Metropolitanas) que pudieran tener a su cargo la gestión de la red de aguas residuales en las que se producen tales vertidos, o de las competencias que correspondan a la propia Administración autonómica en materia de saneamiento ${ }^{36}$.

Respecto a las competencias municipales sobre los vertidos indirectos a la red de saneamiento municipal se nos plantea la duda de cuáles son realmente los términos de esta atribución competencial. Si comparamos la dicción del Art. 81.1.f) (que atribuye a la Comunidad Autónoma "el otorgamiento de las autorizaciones de vertido y el control y seguimiento de las condiciones establecidas en ellas") con la del Art. 81.2 (según el cual corresponde al Municipio "el control y seguimiento de vertidos a la red de saneamiento..."), notamos que en este segundo caso no se menciona expresamente la competencia para otorgar las autorizaciones de vertido. ¿Quiere ello decir que no se inclu-

\footnotetext{
${ }^{34}$ Recordemos que la LBRL establece en su Art. 25.2 que el Municipio ejercerá competencias "en los términos de la legislación del Estado y de las CCAA" sobre "el alcantarillado y tratamiento de aguas residuales"; en el Art. 26.1.a), configura como servicio municipal de prestación obligatoria el alcantarillado; y en el Art. 86.3 reserva en favor de las Entidades locales el servicio esencial de depuración de aguas.

${ }^{35}$ Ciertamente el Art. 81.2 habla de vertidos realizados "a la red de saneamiento municipal".

${ }^{36}$ Según establece el Art. 50.2 del nuevo Estatuto de Andalucía de 2007, corresponde a la Comunidad Autónoma de Andalucía “... dentro de su ámbito territorial la competencia ejecutiva sobre adopción de medidas adicionales de protección y saneamiento de recursos hídricos y de los ecosistemas acuáticos...”.
} 
ye tal facultad entre las que se atribuyen al municipio? Nos parece que quizá la LGICA debería haber sido más clara en este punto, teniendo en cuenta que se trata de una cuestión que hasta la fecha ha sido muy controvertida.

En efecto, la Ley de Aguas, aunque asignaba la competencia para otorgar las autorizaciones de vertido a la Administración hidráulica ${ }^{37}$, no mencionaba expresamente a los vertidos realizados al alcantarillado municipal o red de saneamiento municipal. Ante el silencio del legislador, el Reglamento del Dominio Público Hidráulico (RDPH) -aprobado por RD 849/1986, de 11 de abril - atribuyó expresamente la competencia para otorgar tales autorizaciones "al órgano autonómico o local competente" (Art. 245.2 in fine) ${ }^{38}$. Sin embargo, esta atribución competencial, realizada vía reglamentaria, daría lugar al planteamiento de un recurso contencioso-administrativo contra el citado artículo. Dicho recurso fue estimado mediante STS de 18 de octubre de 2006, la cual anuló el inciso final del precepto reglamentario en cuestión, por entender que violaba la Ley 7/1985, reguladora de las Bases del Régimen Local (concretamente los arts. 2.2 y 25.3) según la cual sólo una norma legal puede determinar las competencias que corresponden al Municipio. La STS citada motivó la aprobación, mediante RD Ley 4/2007, de 13 de abril, de una modificación del Art. 100.2 del TRLA, que ahora reza así: "Las autorizaciones de vertido corresponderán a la Administración hidráulica competente, salvo en los casos de vertidos efectuados en cualquier punto de la red de alcantarillado o de colectores gestionados por las Administraciones autonómicas o locales o por entidades dependientes de las mismas, en los que la autorización corresponderá al órgano autonómico o local competente”. Esta solución resulta lógica teniendo en cuenta que dichos entes son los que gestionan la red de aguas residuales a la que van a parar tales vertidos. No tiene sentido pensar que el control de los mismos quede en manos de otras administraciones. Por

37 Según establece su Art. 17.d) corresponde al Estado "el otorgamiento de autorizaciones referentes al dominio público hidráulico, así como la tutela de éste, en las cuencas hidrográficas que excedan del ámbito territorial, de una sola Comunidad Autónoma. La tramitación de las mismas podrá, no obstante, ser encomendada a las Comunidades Autónomas; y en su Art. 24 a), entre las atribuciones y cometidos de los organismos de cuenca incluye "el otorgamiento de autorizaciones y concesiones referentes al dominio público hidráulico, salvo las relativas a las obras y actuaciones de interés general del Estado, que corresponderán al Ministerio de Medio Ambiente”.

38 Decía, refiriéndose a la autorización de vertido “... Dicha autorización corresponde al Organismo de cuenca tanto en el caso de vertidos directos a aguas superficiales o subterráneas como en el de vertidos indirectos a aguas subterráneas. Cuando se trata de vertidos indirectos a aguas superficiales, la autorización corresponderá al órgano autonómico o local competente". 
ello, en aplicación de esa doctrina del Tribunal Supremo, lo lógico es que la LGICA hubiera precisado con mayor claridad que la competencia para autorizar los vertidos indirectos a la red de alcantarillado o a colectores corresponde a la Administración que gestiona el servicio.

\section{INSTRUMENTOS JURÍDICOS AL SERVICIO DE LA PROTEC- CIÓN DE LA CALIDAD DE LAS AGUAS}

Tal como se desprende de la EM de la LGICA, la tutela de la calidad ambiental en la Comunidad Autónoma de Andalucía tiene fundamentalmente un carácter preventivo. La prevención se manifiesta como el mecanismo más adecuado de intervención. Por ello, las técnicas de actuación previstas por el legislador se dirigen sobre todo a evitar el daño ambiental antes de que se produzca.

La Ley andaluza contempla diferentes instrumentos jurídicos encaminados a mejorar la calidad del medio hídrico. Entre todos ellos ocupa un lugar destacado la autorización de vertido, que constituye sin duda la técnica de mayor relevancia, con protagonismo destacado, que se refleja en el propio articulado de la Ley ${ }^{39}$. Junto a ella, la normativa andaluza prevé otras medidas complementarias. Veamos cuáles son: en primer lugar, podríamos citar las técnicas de planificación o programación ${ }^{40}$, como los programas de seguimiento

\footnotetext{
${ }^{39}$ De las dos secciones en que queda dividido el Capítulo III (Título IV) de la Ley, una de ellas está dedicada a los "Vertidos", con lo cual, desde el punto de vista cuantitativo, la mitad del capítulo está dedicado a regular esta técnica.

${ }^{40}$ Como ya hemos señalado y, aunque la LGICA no los menciona expresamente, uno de los instrumentos al servicio de la protección de la calidad de las aguas son los Planes hidrológicos. Entre sus contenidos se incluyen numerosas determinaciones relativas a la protección de los recursos hídricos, como por ejemplo, los objetivos ambientales establecidos para las diferentes masas de agua. Teniendo en cuenta que dichos objetivos deberán respetarse al otorgar las correspondientes autorizaciones de vertido, se comprende la interconexión existente entre la planificación hidrológica y la tutela ambiental de las aguas.

En relación a los "objetivos ambientales" puede verse el trabajo de la Prof. HORGUÉ BAENA, C. ("Los objetivos medioambientales" en Derecho de Aguas, IEA, Murcia, 2006, pp. 868-869), quien afirma que: "Tales objetivos medioambientales se erigen en los elementos determinantes o valorativos de la calidad de las aguas, noción ésta de la calidad a la que prácticamente sustituyen, pues estos objetivos son los que definen el deber ser de las aguas desde el viso ambiental. A modo de síntesis o idea fuerza puede señalarse que se trata de conseguir que en toda la Comunidad las aguas presenten un estado, al menos, bueno. Y por esta razón, estos objetivos medioambientales se erigen en los ejes que vertebran todo el complejo entramado normativo que establece la Directiva Marco de Aguas, a cuyo logro se dirige".
} 
del estado de las aguas previstos en el Art. 82 de la Ley ${ }^{41}$, los programas de reducción de la presencia de sustancias peligrosas (Art. 81.2.a) ${ }^{42}$, o los programas de actuación para prevenir la contaminación de origen difuso, del Art. $83^{43}$; en segundo lugar, el establecimiento de prohibiciones -como la de realizar vertidos- (Arts. 85 y 86); tercero, las técnicas de verificación y control, como la vigilancia, control y seguimiento de la calidad de las aguas, a las que se refiere el Art. 81.1. d); además, cabe mencionar el establecimiento de deberes de información, establecidos por ejemplo para los titulares de vertidos en relación a las condiciones en las que vierten (Art. 88.g); y, finalmente, las técnicas correctivas, reguladas en los Arts. 81.1.g) y Arts. 140-142 que tipifican las infracciones y sanciones en materia de calidad del medio hídrico.

Esta lista podría completarse con otros instrumentos jurídicos que encontramos salpicados a lo largo de la LGICA y que también pueden coadyuvar a mejorar la calidad ambiental de las aguas. Por citar algunos ejemplos: los instrumentos de prevención y control ambiental regulados en los Arts. 15 y ss. de la Ley (autorización ambiental integrada, autorización ambiental unificada, evaluación ambiental de planes y programas, calificación ambiental y autorización de control de la contaminación ambiental), técnicas de indudable importancia y que habrá que conectar -como veremos más adelante- con las previstas en el Capítulo III; las exigencias y garantías establecidas en la norma an-

${ }^{41}$ La LGICA establece que los programas de seguimiento del estado de las aguas comprenderán el seguimiento del estado ecológico y químico de las aguas continentales, de transición y costeras y el estado químico de las aguas territoriales. Asimismo ordena que se elaboren periódicamente informes sobre el estado de las aguas para lo que se podrá recabar información de otros organismos. A fin de posibilitar el seguimiento de la calidad de las aguas se podrá disponer de los dispositivos de vigilancia y control que se requieran, que serán considerados de interés público, pudiendo imponerse las servidumbres que resulten necesarias.

${ }^{42} \mathrm{Su}$ establecimiento en relación a la red de alcantarillado de saneamiento municipal corresponde a los Municipios.

${ }^{43}$ Los programas de actuación para prevenir y reducir la contaminación de origen difuso se establecerán "en todo caso, en las zonas designadas como vulnerables, de acuerdo con la normativa sobre contaminación por nitratos de origen agrario" (Art. 83.2). Tales programas tendrán carácter vinculante ("serán de obligado cumplimiento") una vez que se aprueben y hagan públicos (Art. 83.3).

Mediante Decreto 261/1998, de 15 de diciembre, se designaron en Andalucía las zonas vulnerables a la contaminación por nitratos procedentes de fuentes agrarias y por Orden de 27 de junio de 2001, conjunta de las Consejerías de Medio Ambiente y de Agricultura y Pesca, se aprobó el Programa de Actuación aplicable en dichas zonas vulnerables. 
daluza en relación a la información ambiental (Arts. 5 y ss.); el fomento de la investigación, innovación y desarrollo tecnológico en la generación y aplicación de nuevos conocimientos sobre el medio ambiente (Arts. 11-12); el fomento de la formación y educación ambiental de los ciudadanos de modo que propicien el empleo de buenas prácticas ambientales y la realización de conductas responsables y solidarias, respetuosas con el medio (Arts. 13 y 14); los acuerdos voluntarios ${ }^{44}$, controles voluntarios y distintivos de calidad ambiental (Arts. 111 y ss.); y los incentivos económicos (Art. 119).

\section{LA AUTORIZACIÓN DE VERTIDO}

Dentro del Capítulo III de la LGICA, ocupa un lugar destacado la regulación de los vertidos ${ }^{45}$. No podía ser de otra manera. En la actualidad, los vertidos son la causa fundamental y más generalizada de alteración de las aguas, el mayor agente potencial de contaminación de los recursos hidráulicos.

La regulación establecida en los artículos 84 a 88 de la LGICA tiene el carácter de legislación de desarrollo de la normativa básica estatal en materia de vertidos incluida en el TRLA. En términos generales, el contenido de la ley andaluza resulta muy similar al de la ley de aguas, aunque también se introducen algunas particularidades. El Art. 84 de la LGICA determina cuál es su ámbito de aplicación, incluyendo a los vertidos que se realicen directa e indirectamente en las aguas continentales y litorales ${ }^{46}$, con la única excepción de los

\footnotetext{
${ }^{44}$ Sobre el tema en general puede consultarse SÁNCHEZ SÁEZ, J.A. "Los convenios administrativos para la protección ambiental". IAAP, Sevilla, 2004.

${ }^{45}$ Sobre el tema de los vertidos puede consultarse con carácter general la excelente monografía de CASADO CASADO, L. Los vertidos en aguas continentales. Las técnicas de intervención administrativa. Comares, Granada, 2004, y la bibliografía allí citada; también de la misma autora, La regulación de los vertidos en aguas continentales en el Derecho Comunitario. Hacia un enfoque integral y global en la protección de las aguas. CEDECS, Barcelona, 2005. Además, FANLO LORAS, A.: "La protección de la calidad de las aguas en el ordenamiento jurídico español: algunas consideraciones en relación con el régimen jurídico de los vertidos", en El Derecho Administrativo en el umbral del siglo XXI. Homenaje al Prof. Dr. Ramón Martín Mateo. Tomo III, Tirant lo Blanch, Valencia, 2000, pp. 3517-3541; FORTES MARTÍN, A.: Vertidos y calidad ambiental de las aguas. Regulación jurídico-administrativa. Atelier, Barcelona, 2005.

${ }^{46}$ Respecto a los vertidos marinos, la Disposición final quinta de la Ley Orgánica 42/2007, de 13 de diciembre, del Patrimonio Natural y de la Biodiversidad ha añadido una nueva Disposición adicional novena a la Ley 22/1988, de 28 de julio, de Costas en la que se establecen medidas pa-
} 
vertidos realizados sobre estas últimas desde buques y aeronaves, que se regirán por su legislación específica.

\subsection{La prohibición de realizar vertidos}

La Ley establece con carácter general la prohibición de realizar vertidos. Dicha prohibición sólo podrá levantarse mediante la obtención de la correspondiente autorización de vertido. Se busca así el equilibrio entre el respeto al libre ejercicio de actividades económicas y la protección de los recursos naturales. A través de la autorización de vertido y, dado que resultaría muy difícil la eliminación total de cualquier vertido, el legislador persigue limitar sus efectos nocivos permitiendo que se realicen sólo si reúnen determinadas condiciones.

Según dispone el Art. 85.1 de la LGICA quedan prohibidos los vertidos, cualquiera que sea su naturaleza y estado físico, que se realicen, de forma directa o indirecta, a cualquier bien del dominio público hidráulico o, desde tierra, a cualquier bien del dominio público marítimo terrestre y que no cuenten con la correspondiente autorización administrativa.

Como puede observarse, los términos en los que se formula la prohibición resultan muy amplios. Se prohiben todo tipo de vertidos ${ }^{47}$, tanto directos $\operatorname{como~indirectos~}^{48}$, ya sean realizados en las aguas continentales o en cualquier

ra reducir la contaminación por vertidos de sustancias peligrosas al medio marino y se determinan los objetivos de calidad del medio receptor para los vertidos realizados desde tierra a las aguas interiores del litoral y al mar territorial que puedan contener una o varias de las sustancias peligrosas incluidas en el anexo I, así como los métodos de medida y los procedimientos de control. Según determina el apartado segundo de esta nueva disposición, las autorizaciones de vertido otorgadas por los órganos competentes de las Comunidades Autónomas fijarán, para cada una de las sustancias peligrosas del anexo I presentes en los vertidos, los valores límite de emisión, que se determinarán tomando en consideración los objetivos de calidad recogidos en dicho anexo así como aquellos que, adicionalmente, fijen o hayan fijado las Comunidades Autónomas.

${ }^{47}$ Urbanos, industriales, agropecuarios.

48 Son vertidos directos los que conllevan la emisión directa de contaminantes a las aguas continentales o cualquier otro elemento del dominio público, así como la descarga de contaminantes en el agua subterránea mediante inyección sin percolación a través del suelo o del subsuelo. Son vertidos indirectos los realizados a través del alcantarillado, sistema de saneamiento, aguas pluviales o cualquier otro elemento de desagüe, así como los realizados en aguas subterráneas mediante filtración a través del suelo o del subsuelo. Vid. Art. 254.1 RDPH. 
otro elemento del dominio público hidráulico ${ }^{49}$, como en aguas litorales, ya se trate de vertidos tanto en aguas superficiales como subterráneas, cualquiera que sea su naturaleza ${ }^{50}$ y estado físico ${ }^{51}$.

La redacción del precepto es muy parecida a la del Art. 100 del TRLA. No obstante, entendemos que la LGICA introduce alguna novedad, ya que establece la prohibición del vertido a secas, omitiéndose -no sabemos si intencionadamente o no- la referencia que hace la Ley estatal al vertido "de aguas y productos residuales susceptibles de contaminar". El dato es importante, ya que en principio está prohibida la realización del vertido, sea o no sea contaminante. Con lo cual se despejan las dudas que plantea la valoración de la potencialidad dañina del vertido. Si esto es así la norma autonómica añadiría un plus de protección sobre la regulación estatal.

La LGICA define el concepto de contaminación hídrica en su Art. 79.5 como la acción y el efecto de introducir materias o formas de energía, o inducir condiciones en el medio hídrico que, de modo directo o indirecto impliquen una alteración perjudicial de su calidad en relación con los usos posteriores, con la salud humana, o con los ecosistemas acuáticos o terrestres directamente asociados a los acuáticos; causen daños a los bienes; y deterioren o dificulten el disfrute y los usos del medio ambiente ${ }^{52}$. Se trata de un concepto ciertamente amplio $^{53}$, en el que aparecen numerosos elementos indeterminados.

\footnotetext{
${ }^{49} \mathrm{Si}$ seguimos el tenor literal del precepto, quedarían fuera de la prohibición del Art. 85.1 los vertidos en cauces privados o en cualquier otro elemento del dominio privado. En este sentido nos parece acertada la posición de CASADO CASADO, L. quien refiriéndose al TRLA critica esta reducción y aboga por una interpretación amplia acorde con el espíritu proteccionista de la norma (Los vertidos en aguas continentales... ob. cit. pp. 19-20).

${ }^{50}$ El término "naturaleza" parece emplearse en sentido material y no jurídico (lo que nos llevaría a determinar el tipo de uso del dominio público hidráulico-común especial o privativo-que conlleva la acción de vertido).

${ }^{51}$ Es decir, efluentes líquidos, gaseosos o incluso sólidos. En relación a los desechos sólidos véase la normativa sobre residuos.

52 El concepto es prácticamente idéntico al del Art. 93 del TRLA, con la única diferencia de que la LGICA, al referirse a la acción de contaminar, sustituye la expresión "en el agua" por la de "en el medio hídrico".

${ }^{53}$ Vid. CASADO CASADO, L. quien destaca la vaguedad, indefinición y falta de precisión de muchos de los términos utilizados por el TRLA (Los vertidos en aguas continentales... ob. cit. p. 14 y ss.).
} 
En principio, la prohibición de realizar vertidos tiene carácter relativo, ya que se puede levantar mediante autorización administrativa. En algún caso, dicha prohibición podría transformarse en prohibición absoluta, extendiéndose también a la realización misma de actividad industrial, no ya al vertido. Nos referimos al supuesto previsto en el Art. 86 de la LGICA, en el que se otorga al Consejo de Gobierno la facultad de prohibir, en zonas concretas, aquellas actividades y procesos industriales cuyos efluentes, a pesar del tratamiento a que sean sometidos, puedan constituir riesgo de contaminación grave para las aguas, bien sea en su funcionamiento normal o en caso de situaciones excepcionales previsibles ${ }^{54}$.

En el caso de vertidos realizados en aguas subterráneas, el régimen de protección se intensifica, y también la prohibición de vertido se convierte en prohibición casi absoluta, ya que sólo puede levantarse y, en consecuencia, el vertido autorizarse, si se demuestra su inocuidad ${ }^{55}$.

\subsection{La autorización de vertido: una autorización condicionada}

La autorización de vertido ${ }^{56}$ constituye uno de los principales mecanismos de control medioambiental, manifestación patente del principio de prevención y ejemplo paradigmático de "autorización ambiental" 57 .

\footnotetext{
${ }^{54}$ En el mismo sentido, el párrafo segundo del Art. 103 del TRLA, atribuye dicha facultad en favor del Gobierno. Se trata sin duda de una medida de carácter excepcional, ligada a situaciones extraordinarias.

${ }^{55}$ Así lo ordena el Art. 85.5 de la LGICA: "Cuando el vertido pueda dar lugar a la infiltración o almacenamiento de sustancias susceptibles de contaminar los acuíferos o las aguas y capas subterráneas, sólo podrá autorizarse si el estudio hidrogeológico previo demuestra su inocuidad" (en términos muy parecidos se expresa el Art. 102 del TRLA).

56 Sobre el tema consúltese la voz "Autorización de Vertidos", a cargo de FORTES MARTÍN, A: en EMBID IRUJO, A. (Dir.): Diccionario de Derecho de Aguas. Iustel, Madrid, 2007, pp. 265-282. También del mismo autor, "La caracterización técnica y ambiental del régimen de vertidos a las aguas: algunas precisiones jurídicas", en EMBID IRUJO, A. (Dir.): Conflictos jurídicos en la gestión y uso del agua. Estudios de Derecho Judicial $\mathrm{n}^{\circ}$ 97. Consejo General del Poder Judicial, Madrid, 2007, pp. 191-244.

${ }^{57}$ Así lo afirma CASADO CASADO, L. Los vertidos en aguas continentales... ob. cit. p. 374, quien considera que en las autorizaciones de vertido podemos encontrar los rasgos característicos y definitorios de las autorizaciones ambientales. En efecto, estamos ante una autorización que recae sobre actividades susceptibles de provocar la contaminación del dominio público hidráulico; su
} 
Como se ha señalado anteriormente, su otorgamiento corresponde a la Administración General del Estado (Art. 17.d) del TRLA) -competencia que ejercerá a través del Organismo de cuenca (Art. 24 a) del TRLA) - si el vertido es directo y se realiza en una cuenca intercomunitaria ${ }^{58}$; a la Comunidad Autónoma de Andalucía (D.A. $2^{\text {a }}$ TRLA y Art. 81.1.f) de la LGICA) en caso de vertidos directos en cuencas intracomunitarias; $y$, finalmente, al municipio respecto a los vertidos indirectos a la red de saneamiento municipal (Art. 81.2 de la LGICA).

La autorización de vertidos a aguas litorales y continentales se califica y tipifica en la LGICA como una "autorización de control de la contaminación ambiental" 59 (junto con la autorización de emisiones a la atmósfera, la autorización de producción de residuos y la autorización de gestión de residuos). Se regula en los Arts. 84 a $85^{60}$. De su lectura pueden inferirse las principales notas características que conforman su régimen jurídico ${ }^{61}$ :

En primer lugar, la autorización de vertido se otorgará teniendo en cuenta las mejores técnicas disponibles y de acuerdo con las normas de calidad del medio hídrico y los límites de emisión fijados reglamentariamente ${ }^{62}$. Con es-

otorgamiento o denegación los realizará la Administración sobre la base de los parámetros normativos existentes; y además, una vez otorgada la autorización, perdura el control administrativo sobre la actividad, para garantizar una adecuación permanente a las condiciones previstas en la normativa aplicable y a las recogidas en el propio acto administrativo.

58 Volvemos a hacer la salvedad incluida en la nota 30 respecto a la cuenca del Guadalquivir.

59 (Art. 46 LGICA).

${ }^{60}$ Dicha regulación es aplicable a los supuestos de actuaciones no sometidas a autorización ambiental integrada y autorización ambiental unificada, tal como se deduce de lo dispuesto por el Art. 47.1 de la LGICA. Más adelante analizaremos las relaciones de la autorización de vertido con tales autorizaciones.

61 Vid. el trabajo de CASADO CASADO, L. Los vertidos en aguas continentales... ob. cit., p. 377 y ss. Aunque las reflexiones en él contenidas se realizan a partir del TRLA, entendemos que las conclusiones a que llega la autora resultan trasladables a la autorización de vertido regulada por la LGICA.

${ }^{62}$ El Real Decreto 907/2007, de 6 de julio, por el que se aprueba el Reglamento de la Planificación Hidrológica, ha establecido en su Anexo IV la Lista de sustancias peligrosas -dicha lista se mantiene en vigor hasta tanto no sea modificada por las que, sobre sustancias peligrosas, sean aprobadas en aplicación de la Directiva 2000/60/CE- y en su Anexo V las clasificaciones del estado ecológico (muy buen estado, buen estado y estado moderado) para ríos, lagos, aguas de tran- 
te aserto, se introduce para el otorgamiento de la autorización el denominado enfoque combinado, que supone valorar no sólo los límites de emisión del efluente sino también los objetivos de calidad establecidos para el medio receptor (para cada tipo de masas de agua). El logro de dichos objetivos constituye en realidad la finalidad última de la autorización de vertido -por ello, las condiciones de vertidos serán más rigurosas cuando el cumplimiento de los objetivos medioambientales así lo requiera-. También implica condicionar la autorización de vertido al empleo por parte de su titular de las mejores tecnologías existentes para reducir o eliminar la contaminación de las aguas ${ }^{63}$.

En segundo lugar, estamos ante una "autorización condicionada", en la medida en que la autorización de vertido se somete a una serie de condiciones específicas impuestas por la Administración otorgante y de cuyo cumplimiento depende que pueda realizarse válidamente el vertido autorizado. Lo expresa claramente el Art. 85.3 de la LGICA, cuando dice: "Las autorizaciones de vertido establecerán las condiciones en que éste debe realizarse. En todo caso, deberán especificar los elementos de control, el caudal de vertido auto-

sición y aguas costeras, expresivas de la calidad de las aguas, y que habrán de tenerse en cuenta a efectos del otorgamiento de las autorizaciones de vertido.

Véase al respecto la Directiva 2006/11/CE, de 15 de febrero sobre la contaminación causada por determinadas sustancias peligrosas vertidas en el medio acuático de la Comunidad.

63 Estos tres elementos (la consecución del buen estado ecológico de las aguas, el cumplimiento de las normas de calidad ambiental de las aguas, y el empleo de las mejores técnicas disponibles) llevan a FORTES MARTÍN, A. a considerar que, por influencia de la Directiva 2000/60, se ha establecido en nuestro Derecho una nueva caracterización del régimen de los vertidos, que él califica de "técnica” y "ambiental" (Vid. "La caracterización técnica y ambiental del régimen de vertidos a las aguas...", cit. p. 208 y ss).

La Directiva 2008/1/CE, de 15 enero, de Prevención y control integrados de la contaminación ha definido en su Art. 2.12 las «mejores técnicas disponibles» como "la fase más eficaz y avanzada de desarrollo de las actividades y de sus modalidades de explotación, que demuestren la capacidad práctica de determinadas técnicas para constituir, en principio, la base de los valores límite de emisión destinados a evitar o, cuando ello no sea practicable, reducir en general las emisiones y el impacto en el conjunto del medio ambiente. También se entenderá por:

a) «técnicas»: la tecnología utilizada junto con la forma en que la instalación esté diseñada, construida, mantenida, explotada y paralizada;

b) «disponibles»: las técnicas desarrolladas a una escala que permita su aplicación en el contexto del sector industrial correspondiente, en condiciones económica y técnicamente viables, tomando en consideración los costes y los beneficios, tanto si las técnicas se utilizan o producen en el Estado miembro correspondiente como si no, siempre que el titular pueda tener acceso a ellas en condiciones razonables;

c) «mejores»: las técnicas más eficaces para alcanzar un alto nivel general de protección del medio ambiente en su conjunto". 
rizado, así como los límites cuantitativos y cualitativos que se impongan a la composición del efluente y la exigencia de comprobación previa a la puesta en marcha de la actividad de aquellos condicionantes que se estimen oportunos" ${ }^{\prime 4}$. En este punto resulta fundamental el sistema de estándares o niveles de contaminación que necesariamente acompañará a las autorizaciones ${ }^{65}$. La Administración puede además establecer unas condiciones de vertido más severas o rigurosas cuando el cumplimiento de los objetivos ambientales así lo requiera, tal como permite el Art. 85.2 in fine.

Así pues, la autorización de vertido no supone una habilitación para contaminar, ni un cheque en blanco para realizar el vertido en cualesquiera condiciones. Todo lo contrario, el título habilitante para realizar el vertido viene acompañado de un paquete de condiciones sin cuyo cumplimiento carece de validez el vertido para el que se ha solicitado la autorización previa. Por ello, resulta muy conveniente la previsión que hace el Art. 85.3 in fine respecto a la exigencia de comprobación previa a la puesta en marcha de la actividad de aquellos condicionantes que se estimen oportunos ${ }^{66}$ (pensamos, por ejemplo, en la construcción de las instalaciones de depuración necesarias).

El condicionado de la autorización es de tal relevancia que la LGICA realiza constantes alusiones a su contenido ${ }^{67}$. Su cumplimiento no sólo debe observarse en el momento del otorgamiento de la autorización sino también mantenerse durante el plazo de vigencia de la misma. Para asegurarlo, la Ley

${ }^{64}$ El Art. 101.1 párrafo segundo del TRLA también establece un contenido mínimo para este condicionado, al señalar: "En todo caso, deberán especificar las instalaciones de depuración necesarias y los elementos de control de su funcionamiento, así como los límites cuantitativos y cualitativos que se impongan a la composición del efluente y el importe del canon de control de vertido definido en el Art. 113".

65 Véase CASADO CASADO, L. Los vertidos en aguas continentales... ob.cit., p. 378.

${ }^{66}$ La expresión empleada por la LGICA induce a pensar que la Administración cuenta con un amplio margen de apreciación para determinar dichas condiciones.

${ }^{67}$ Además de la referencia expresa del Art. 85.3 ya aludida, el mismo Art. 85.2 in fine, permite el establecimiento de "condiciones de vertido" más rigurosas cuando el cumplimiento de los objetivos medioambientales así lo requiera; el Art. 87 faculta a la Consejería competente en materia de medio ambiente para modificar, con carácter general, "las condiciones de vertido" a fin de garantizar los objetivos de calidad; o el Art. 88 que, al enumerar las obligaciones que asume el titular de la autorización de vertido, se remite a "los términos establecidos en el condicionado de la autorización" (aptdo. a) o a "las condiciones en las que se vierten" (aptdo. g). 
reserva a la Administración una serie de facultades de intervención (v. g. solicitar información, efectuar los controles e inspecciones que estime convenientes, revisar la autorización).

Las autorizaciones de vertido quedan supeditadas además a la normativa en cada momento en vigor y a la utilización de las mejoras técnicas disponibles. Muestra de ello es que, tal como establece el Art. 87.1.c) de la LGICA, la autorización puede ser objeto de revisión para adecuar el vertido a las normas de calidad ambiental y objetivos de calidad de las aguas que sean aplicables en cada momento.

Esta subordinación de la actividad autorizada a las modificaciones normativas que se produzcan, convierte a la autorización de vertido en un instrumento de carácter extraordinariamente dinámico y vulnerable ${ }^{68}$. El titular del vertido no adquiere ningún derecho a contaminar ${ }^{69}$.

En tercer lugar, la autorización de vertido instaura una relación jurídica continuada entre la Administración otorgante y el sujeto autorizado ${ }^{70}$. Durante la vigencia de la autorización, la Administración ejercerá un control sobre la actividad autorizada, y el titular de la autorización por su parte deberá realizar una serie de actuaciones que facilitarán esa labor de vigilancia y verificación sobre las condiciones del vertido. Así por ejemplo, entre las obligaciones que incumben al titular del vertido, la LGICA incluye la de realizar una declaración anual de vertido (Art. 88 c); la de comunicar al órgano competente los vertidos accidentales que se produzcan (Art. 88, e); o la de informar periódicamente a la Administración sobre las condiciones en que se vierte (Art. 88 g).

La relación jurídica que surge a raíz del otorgamiento de la autorización de vertido no se prolonga en el tiempo de forma indefinida, sino que queda sometida a un plazo de vigencia, que el TRLA fija en cinco años (Art. 101.3) ${ }^{71}$.

68 Véase CASADO CASADO, L. Los vertidos en aguas continentales... ob.cit., p. 379.

69 CASADO CASADO, L. quien mantiene el carácter constitutivo de la autorización de vertido. Vid. Los vertidos en aguas continentales... ob.cit., p. 382.

${ }^{70}$ Vid. CASADO CASADO, L. Los vertidos en aguas continentales... ob.cit., p. 380.

${ }^{71}$ Sobre el carácter temporal de la autorización de vertido vid. CASADO CASADO, L. Los vertidos en aguas continentales... ob.cit., p. 381. 
La LGICA no dice nada sobre este punto, ni tampoco contiene mención alguna sobre la posibilidad de renovación de la autorización, una vez finalizado el plazo para el cual se otorgó y, una vez que se haya comprobado que se cumplen las normas de calidad y los objetivos ambientales exigibles en cada momento, por lo que debemos entender que resultan de aplicación las previsiones establecidas al respecto por la ley estatal.

En cuarto lugar, se trata de una autorización en la que aparecen elementos reglados y discrecionales, aunque abundan estos últimos. En efecto, por una parte la Administración está vinculada por las normas de calidad, los objetivos ambientales y las características de emisión e inmisión establecidas normativamente, y no podrá autorizar vertidos que no se ajusten a dichas previsiones. Por otra, ciertamente dispone de un margen de apreciación para valorar las condiciones de vertido, establecer las que estime oportunas o imponer condiciones más rigurosas. Tal facultad de valoración se incardina en la denominada "discrecionalidad técnica"72.

La concurrencia de todas estas notas características lleva a CASADO CASADO, L. a afirmar que, a pesar de la denominación utilizada por nuestro ordenamiento jurídico y teniendo en cuenta su régimen jurídico, "la autorización de vertido podría calificarse como una cuasiconcesión o, como "autorización-concesional"73. "La autorización de vertido constituye una figura que por su régimen jurídico, se acerca mucho a una verdadera concesión. En ella podemos identificar elementos típicamente concesionales...". "Así, su carácter constitutivo y la inexistencia de un derecho a contaminar en la esfera jurídica del vertedor; la presencia de importantes elementos discrecionales, que confieren a la Administración un amplio margen a la hora de la determinación de su contenido; la limitación del período de vigencia; la relación jurídica continuada entre Administración y autorizatario; el amplio poder conformador atribuido por el ordenamiento jurídico a la Administración Pública, que puede revisar, modificar o revocar la autorización para garantizar su permanente adecuación al interés público; y la extraordinaria mutabilidad y vulnerabilidad de la situación jurídica otorgada al particular. Ahora bien, también identificamos algunos elementos, menos, típicos de la autorización"74.

\footnotetext{
72 Véase CASADO CASADO, L. Los vertidos en aguas continentales... ob.cit., pp. 383-386.

${ }^{73}$ Cfr. Los vertidos en aguas continentales... ob.cit., p. 395.

${ }^{74}$ Cfr. Los vertidos en aguas continentales... ob.cit., p. 394.
} 


\subsection{Obligaciones del titular de la autorización de vertido}

Constituyen una manifestación de la relación jurídica existente entre la Administración y el titular de la autorización, relación que se prolonga en el tiempo hasta el vencimiento del plazo autorizatorio o aquella no se revoque o extinga por otra causa.

Las obligaciones de los titulares de la autorización de vertido se establecen directamente por la Ley (Art. 88), aunque algunas de ellas se concretarán lógicamente en la propia autorización de vertido. Son las siguientes: a) Instalar y mantener en correcto funcionamiento los equipos de vigilancia de los vertidos y de la calidad del medio en los términos establecidos en el condicionado de la autorización de vertido; b) Evitar la acumulación de compuestos tóxicos o peligrosos en el subsuelo o cualquier otra acumulación que pueda ser causa de degradación del dominio público hidráulico; c) Realizar una declaración anual de vertido cuyo contenido se determinará reglamentariamente ${ }^{75}$; d) Ejecutar a su cargo los programas de seguimiento del vertido y sus efectos establecidos, en su caso, en la autorización; e) Adoptar las medidas adecuadas para evitar los vertidos accidentales y, en caso de que se produzcan, corregir sus efectos y restaurar el medio afectado, así como comunicar dichos vertidos al órgano competente en la forma que se establezca; f) Constituir una fianza a fin de asegurar el cumplimiento de las condiciones impuestas en la autorización, con las excepciones previstas en la normativa aplicable, y sin perjuicio del abono de los tributos exigibles ${ }^{76}$; g) Informar, con la periodicidad, en los

${ }^{75}$ El RDPH (Art.246.1, en la redacción dada al mismo por el RD 606/2003, de 23 de mayo, por el que se modifica el RD 849/1986, de 11 de abril), incluye la declaración de vertido entre la documentación que el titular del vertido debe acompañar a la solicitud de autorización de vertido presentada ante la Administración. En este caso, la Ley andaluza se está refiriendo no ya a la declaración inicial de vertido, sino a declaraciones periódicas que el titular de la autorización de vertido deberá presentar una vez al año ante la Administración otorgante y mientras dure la vigencia de aquella. A estas declaraciones también alude implícitamente el Art. 101.4, párrafo segundo in fine, del TRLA, al establecer que: "Asimismo, con la periodicidad y en los plazos que reglamentariamente se establezcan, los titulares de autorizaciones de vertido deberán acreditar ante la Administración hidráulica las condiciones en que vierten".

${ }^{76}$ La incorporación de esta obligación al condicionado de la autorización -que responde a los principios de prevención, responsabilidad y al de que quien contamina paga- constituye una novedad de la LGICA respecto a la regulación prevista en el TRLA -no así respecto a otras normas autonómicas reguladoras de la autorización ambiental integrada-. Se trata de establecer una garantía suficiente que permita hacer frente a las obligaciones derivadas de la actividad autorizada. La Ley no indica el momento en el que haya de constituirse tal fianza ni su alcance, pero lo lógico será pensar que deba hacerse antes de que se emita la resolución final autorizatoria. 
plazos y la forma que se establezca, a la Consejería competente en materia de medio ambiente de las condiciones en que se vierten; h) Constituir una junta de usuarios o comunidad de vertidos en los casos que se determine reglamentariamente; i) Separar las aguas de proceso de las sanitarias y de las pluviales salvo que técnicamente sea inviable y se le exima de esta obligación en la correspondiente autorización de vertidos; y, finalmente cualesquiera otras obligaciones establecidas reglamentariamente.

\subsection{El procedimiento autorizatorio}

Para conocer el procedimiento aplicable para el otorgamiento de la autorización de vertido, nuevamente hemos de distinguir según el carácter que tenga la cuenca en la que el vertido va a realizarse $\mathrm{e}^{77}$.

Si se produce sobre una cuenca intercomunitaria, de competencia estatal, la regulación del procedimiento será la establecida en la normativa estatal, en este caso la prevista en el RDPH (Arts. 246-25078), aunque, eso sí, teniendo en cuenta que la Comunidad autónoma puede introducir algunas modulaciones, sobre la base de sus competencias en otras materias sectoriales conexas.

Por lo que respecta a las cuencas intracomunitarias, la norma procedimental exigible para la obtención de la autorización será la establecida de forma específica por la propia Comunidad Autónoma, que deberá respetar aquellas normas procedimentales estatales básicas contenidas en el RDPH. Como ha declarado el TC, en la Sentencia 227/1988, de 29 de noviembre, estas normas, con ciertas salvedades, no tienen carácter básico, por lo que resultan de aplicación supletoria respecto a la legislación que dicten las CCAA con competencias sobre aprovechamientos hidráulicos intracomunitarios (Fdto. Jco. 32).

La LGICA no nos ofrece una regulación general del procedimiento de otorgamiento de la autorización de vertido, por lo que deberá ser objeto de desarrollo reglamentario. Únicamente establece algunas previsiones concretas de carácter procedimental, como son:

77 Puede verse en relación a este tema PONT CASTEJÓN, I. "El procedimiento administrativo de autorización de vertidos a aguas continentales ante el reto de una administración hidráulica eficaz", en Revista Aranzadi de Derecho Ambiental, nº 5, (2004-1), p. 17.

78 Norma modificada por el RD 606/2003, de 23 de mayo. 
En relación a las solicitudes de autorizaciones de vertido de los municipios, o las entidades que tengan asumida la titularidad de los vertidos, el Art. 85.6 de la LGICA establece que contendrán en todo caso un plan de saneamiento y control de vertidos a la red de alcantarillado municipal. La incorporación del plan de saneamiento municipal resulta lógica como medida preventiva y de cara a exigir responsabilidades. Además, las Entidades locales estarán obligadas a informar a la Consejería competente en materia de medio ambiente sobre la existencia de vertidos en los colectores locales de sustancias peligrosas. Ambas exigencias vienen establecidas también por la normativa estatal (Art. 101.5 TRLA y Art. 246.3 RDPH ${ }^{79}$ ). Dichas obligaciones recaen sobre la entidad titular del vertido final, que puede ser un Ayuntamiento u otra entidad supramunicipal (mancomunidad, Área Metropolitana...) con competencia sobre el saneamiento de aguas residuales de los municipios que la integran. También podría darse el caso de que la entidad titular fuera la propia Comunidad Autónoma, con lo cual se daría la circunstancia de que es la misma administración autorizatoria (titular del vertido final) la que a su vez otorga la autorización de vertido.

En cuanto a la documentación que debe acompañar a la solicitud de vertidos que puedan afectar a las aguas subterráneas, de modo implícito, el Art. 85.5 se refiere al estudio hidrogeológico previo que demuestre su inocuidad ${ }^{80}$, estudio que lógicamente deberá aportar el solicitante.

Respecto a la duración del procedimiento, la LGICA establece (Art. 85.7) un plazo de resolución y notificación de la autorización de vertido de seis meses a contar desde la presentación de la solicitud, justo la mitad del plazo de un año fijado por la normativa estatal (Art. 249.2 RDPH).

Transcurrido dicho plazo sin haberse notificado resolución expresa, los interesados podrán entender desestimada su solicitud (Art. 85.7 in fine). La previsión del silencio negativo, que no se recoge expresamente en el TRLA

\footnotetext{
${ }^{79}$ La única diferencia que se observa entre la normativa estatal y la establecida en la ley andaluza es que mientras el Art. 101.5 del TRLA establece la obligación de informar sobre la existencia de vertidos de sustancias peligrosas a la Administración hidráulica, el Art. 85.6 de la LGICA lo hace en favor de la Consejería competente en materia de medio ambiente.

${ }^{80}$ Dice así el citado precepto: "Cuando el vertido pueda dar lugar a infiltración o almacenamiento de sustancias susceptibles de contaminar los acuíferos o las aguas y capas subterráneas, sólo podrá autorizarse si el estudio hidrogeológico previo demuestra su inocuidad”.
} 
aunque sí en el RDPH (Art. 249.2), resulta acertada para garantizar una mayor protección del medio hídrico y ha sido valorada de forma positiva por la doctrina ${ }^{81}$, como solución más acorde con el sentido del Art. 43 de la LRJAP.

\subsection{La revisión de la autorización de vertido}

De acuerdo con el carácter dinámico y condicionado de la autorización de vertido, la LGICA regula la revisión de la autorización de vertido en su Art. 87. La redacción de este precepto, con alguna salvedad, es prácticamente idéntica a la del Art. 104 del TRLA. El Art. 87 atribuye la facultad de revisar la autorización de vertido al "órgano competente para otorgar la autorización de vertido" 82 , en los siguientes casos:

a) Cuando sobrevengan circunstancias que, de haber existido anteriormente, habrían justificado su denegación o el otorgamiento en términos distintos ${ }^{83}$.

b) Cuando se produzca una mejora en las características del vertido y así lo solicite el titular ${ }^{84}$.

${ }^{81}$ Véase CASADO CASADO, L. Los vertidos en aguas continentales... ob.cit., pp. 261-267.

82 El TRLA otorga esta facultad del Organismo de cuenca (Art. 104.1).

83 Aunque indicada para la Autorización ambiental unificada y calificación ambiental, el Art. 19.11 de la LGICA contempla un supuesto de cambio de circunstancias que podrían determinar la revisión de la autorización. Nos referimos a la posibilidad de que se produzca una modificación sustancial -cualquier cambio o ampliación- en la actividad autorizada que pueda tener efectos adversos significativos sobre la seguridad, la salud de las personas o el medio ambiente. Ese mismo precepto considera que existe una "modificación sustancial" cuando en opinión del órgano ambiental competente se produzca, de forma significativa, un incremento de los vertidos a cauces públicos o al litoral y un incremento en la utilización de los recursos naturales. La modificación sustancial de las actuaciones antes referidas queda sometida a autorización ambiental unificada. Para el supuesto de que la modificación no resulte sustancial, el Art. 27.3 de la LGICA somete al requisito de comunicación previa la actuación pretendida. (Sobre el tema de las comunicaciones previas puede verse con carácter general la excelente monografía de NÚÑ̃Z LOZANO, M.C. Las actividades comunicadas a la Administración. La potestad administrativa de veto sujeta a plazo, Marcial Pons, Madrid, 2001).

${ }^{84}$ El Art. 104.1 b) del TRLA se refiere en este supuesto al "interesado". 
c) Para adecuar el vertido a las normas de calidad ambiental ${ }^{85}$ y objetivos de calidad de las aguas que sean aplicables en cada momento ${ }^{86}$.

También prevé ese mismo precepto en su apartado segundo, en casos excepcionales, por razones de sequía o en situaciones hidrológicas extremas, la posibilidad de modificar con carácter general las condiciones de vertido a fin de garantizar los objetivos de calidad. Tal facultad se atribuye a la Consejería competente en materia de medio ambiente.

Como consecuencia de la revisión de la autorización, la Administración podrá, o bien revocar la autorización (en el supuesto previsto en la letra a) del Art. 87.1), o bien modificar el condicionado de la autorización, en cuyo caso debería darse un plazo al titular del vertido para que se adapte a las nuevas condiciones $^{87}$. Dicho plazo podría fijarse reglamentariamente.

No se dice nada en la LGICA respecto a quién corresponde asumir los gastos derivados de la revisión de la autorización ${ }^{88}$, ni tampoco se contiene previsión alguna sobre una cuestión ciertamente delicada como es la de si la revisión debe dar o no lugar a la indemnización a los titulares del vertido por los perjuicios causados. El RDPH determina en su Art. 262.2 que "la modificación del condicionado no dará lugar a indemnización”. Este punto, sin embargo, resulta discutible y dependerá de las circunstancias concretas aplicables al caso ${ }^{89}$. Sería conveniente buscar en este punto una solución viable y que fa-

85 Definidas en la LGICA como los "Niveles de concentración de un determinado contaminante o grupo de contaminantes que no deben superarse en el agua, en los sedimentos o en la biota, con el fin de proteger la salud humana y el medio ambiente” (Art. 79.6).

${ }^{86}$ En este caso, el Art. 104.1 c) añade “y, en particular, a las que para cada río, tramo de río, acuífero o masa de agua dispongan los Planes hidrológicos de cuenca”. Este extremo no se menciona en el texto de la LGICA. No obstante ello, nos parece que, dado el carácter normativo que tienen los PPHHC, los objetivos de calidad por ellos fijados tienen la consideración de normas de calidad ambiental aplicables en cada momento, por lo que habría que entenderlos incluidos dentro de la referencia que el Art. $87.1 \mathrm{c}$ ) realiza a dicha normas.

87 CASADO CASADO, L. Los vertidos en aguas continentales... ob. cit., pp. 328-329.

${ }^{88}$ En el caso de que la revisión se realice previa solicitud de su titular, parece lógico que éste corra con los gastos ocasionados.

89 CASADO CASADO, L. considera, siguiendo a Sánchez Morón que sólo cabría indemnización en aquellos casos en que la revisión viniese impuesta por la revisión de los PPHHC, pero no en los restantes supuestos (Los vertidos en aguas continentales... ob. cit., p. 328 y ss.). 
voreciera al cumplimiento efectivo de los objetivos de protección medioambiental.

\subsection{Regularización de los vertidos existentes}

Con el fin de adecuar gradualmente los vertidos existentes a las prescripciones de la nueva Ley, la LGICA incluye una Disposición Transitoria Tercera bajo el título "Régimen de Regularización de los vertidos existentes", en la cual se establece con carácter general que los vertidos existentes a la entrada en vigor de la Ley deberán adaptarse a lo dispuesto en la misma en el plazo de un año desde su entrada en vigor.

La regulación de un régimen transitorio que permita adecuar los vertidos actuales al nuevo marco normativo establecido en la LGICA resulta conveniente, sobre todo si se quiere asegurar el cumplimiento efectivo de los objetivos de protección de la calidad de las aguas, y evitar que el régimen de protección legal no se ajuste a la realidad fáctica, que a veces nos presenta un panorama desolador en el que existen numerosos vertidos ilegales.

La situación en que se pueden encontrar los titulares de vertido a la entrada en vigor de la ley puede ser diversa: habrá vertidos que cuenten ya con autorización administrativa pero que deban ajustar sus características a la nueva norma; pero también se darán situaciones de ilegalidad, en las que los titulares del vertido no hayan ni siquiera solicitado la correspondiente autorización. La D. T. $3^{\text {a }}$ de la LGICA no distingue entre estos dos tipos de situaciones, simplemente se refiere sin más a los "vertidos existentes" a la entrada en vigor de la Ley. Sin embargo, quizás sería conveniente que en el desarrollo reglamentario de la norma, se introdujeran algunas previsiones al respecto. También debería regularse por vía reglamentaria el procedimiento para llevar a cabo la citada regularización.

\subsection{La autorización de vertido y la autorización ambiental integrada}

Como es sabido, el nuevo planteamiento de la intervención administrativa sobre las actividades contaminantes que adopta la LGICA descansa fundamentalmente sobre la figura de la autorización ambiental integrada (y la autorización ambiental unificada), a través de la cual el legislador pretende realizar una evaluación global de las actividades contaminantes que culmine en 
una resolución única que aglutine el conjunto de autorizaciones sectoriales ambientales exigibles hasta el momento ${ }^{90}$.

Pues bien, no podríamos terminar el comentario que nos ocupa sin hacer alguna referencia, aunque sea breve, a la proyección y la incidencia que tiene dicha autorización sobre la autorización sectorial de vertido. Dado que la autorización ambiental integrada tiene por objeto evitar o, cuando ello no sea posible, reducir y controlar la contaminación de la atmósfera, del agua y del suelo, resulta lógico pensar que el control de las emisiones a las aguas y las condiciones de vertido será uno de los aspectos a tener en cuenta al otorgar dicha autorización. Conviene observar que mientras que la autorización ambiental integrada versa sobre una actividad susceptible de producir un efecto negativo sobre el medio ambiente, en el caso de la autorización de vertido, lo que se autoriza no es la actividad industrial que produce una incidencia medioambiental sino el vertido en sí, es decir, el impacto mismo ${ }^{91}$.

Por ello, a la vista de la regulación establecida en la LGICA, cabe preguntarse: ¿cuáles son las relaciones entre dichas autorizaciones? o, ¿cómo se incardina la autorización de vertido en el procedimiento de otorgamiento de la autorización ambiental integrada?

Para responder a estas preguntas sería necesario distinguir dos hipotéticas situaciones: primera, la de las actividades sometidas al régimen de autorización ambiental integrada o unificada (el control de los vertidos procedentes de estas instalaciones se realizaría a través de dichas autorizaciones); segunda, la del resto de actividades susceptibles de contaminar (las cuales quedarían sometidas a la autorización previa de vertidos regulada en la LGICA). Por otra parte, habría que tener en cuenta si el vertido se realiza en una cuenca intercomunitaria o en una cuenca intracomunitaria, a efectos de determinar la oportuna atribución competencial. En este punto, lo interesante será hacer compatible un enfoque integrado de la contaminación con el respeto a las

${ }^{90}$ La LGICA recoge entre los principios que la inspiran (Art. $3 \mathrm{f}$ ) el "Principio de enfoque integrado, que supone el análisis integral del impacto ambiental de aquellas actividades industriales de alto potencial contaminante".

${ }^{91}$ Esta distinción entre la autorización de vertido y la autorización ambiental integrada la recoge BETANCOR RODRÍGUEZ, A. Instituciones de Derecho Ambiental. Montecorvo, Madrid, 2001, pp. 958-959, cit. por CASADO CASADO, L. Los vertidos en aguas continentales...ob. cit. p. 374. 
competencias de las distintas Administraciones públicas implicadas, estableciendo los oportunos mecanismos de coordinación.

La integración de la autorización de vertido en la autorización ambiental integrada regulada en la LGICA se deduce de lo establecido en el Art. 19.2 de la Ley que ordena la integración en una única resolución de "los pronunciamientos, decisiones y autorizaciones previstos en el Art. 11.1. b) de la Ley 16/2002, de 1 de julio, de prevención y control integrado de la contaminación, y aquellos otros pronunciamientos y autorizaciones que correspondan a la Consejería competente en materia de medio ambiente y que sean necesarios con carácter previo a la implantación y puesta en marcha de las actividades" ${ }^{\text {"2 }}$. El citado Art. 11.1. b) menciona expresamente entre dichas autorizaciones a las autorizaciones de vertido a las aguas continentales, incluidos los vertidos al sistema integral de saneamiento, y la autorización de vertidos desde tierra al mar. En consecuencia, para las actividades sometidas a la autorización ambiental integrada que regula la LGICA, la autorización de vertido se sustituye (porque se integra) por aquella autorización.

La fórmula elegida para dicha integración es la misma que la recogida por la legislación estatal ${ }^{93}$. El Art. 24 de la LGICA, aunque establece alguna

\footnotetext{
${ }^{92}$ En el mismo sentido, véase el Art. 21 c) de la LGICA.

${ }^{93}$ En la legislación estatal (Ley 16/2002, de 1 de julio, de Prevención y control integrados de la contaminación), la integración de la autorización de vertido en la autorización ambiental integrada se lleva a cabo de la siguiente forma:

En las cuencas intracomunitarias, y para aquellas actividades industriales sometidas a la LPCIC la autorización de vertido se sustituye por la autorización ambiental integrada (Art. 11.3 párrafo segundo, de acuerdo con el cual, "las autorizaciones de vertidos a las aguas continentales y al dominio público marítimo terrestre, desde tierra al mar (...) se incluyen en la autorización ambiental integrada, de acuerdo con esta ley"). A estos efectos, la solicitud para la obtención de la autorización ambiental integrada deberá ir acompañada de la documentación exigida por la legislación de aguas para la autorización de vertidos a las aguas continentales y por la legislación de costas para la autorización de vertidos desde tierra al mar (Art. 12.1.c). En dicha autorización se deberán establecer las características y condiciones del vertido, valores límite de emisión, etc.

En relación a las cuencas intercomunitarias, la fórmula de integración elegida por la Ley estatal ha sido la de introducir un informe preceptivo y vinculante del Organismo de cuenca sobre los vertidos, dentro del procedimiento de otorgamiento de la autorización ambiental integrada. Con esta solución, se pretende compaginar la finalidad integradora que persigue la norma con el respeto a la competencia estatal. Por ello, según dispone el Art. 19 de la LPCIC, en aquellos supuestos en los que la actividad sometida a autorización ambiental integrada precise, de acuerdo con la legislación de aguas, autorización de vertido al dominio público hidráulico de cuencas intercomunitarias, el organismo de cuenca competente deberá emitir, en el plazo de seis meses, un in-
} 
particularidad, se remite al procedimiento de integración previsto en la Ley $16 / 2002$, de 1 de julio ${ }^{94}$. Por tanto, podemos concluir que al igual que ocurre en el Estado, la LGICA transforma las autorizaciones de vertido en informes preceptivos y vinculantes que deberán emitirse dentro de los procedimientos para el otorgamiento de la autorización ambiental integrada.

Por otra parte, la integración de la autorización de vertido en la autorización ambiental unificada puede deducirse a su vez del texto del Art. 19.3 de la LGICA, cuando establece que "en la autorización ambiental unificada se integrarán todas las autorizaciones y pronunciamientos ambientales que correspondan a la Consejería competente en materia de medio ambiente y que sean necesarios con carácter previo a la implantación y puesta en marcha de las actuaciones". Entre dichas autorizaciones debe incluirse, como es lógico, la autorización de vertido, cuando su otorgamiento corresponda a la Comunidad Autónoma. No queda, sin embargo, muy claro la forma en que haya de integrarse dicha autorización. El Art. 31.4 de la LGICA, que regula el procedimiento autorizatorio, ordena recabar de los distintos órganos e instituciones los informes que tengan carácter preceptivo de acuerdo con la normativa aplicable, así como aquellos otros que se consideren necesarios. Entre esos informes, lógicamente, se encontrará el que verse sobre las condiciones del vertido. Sin embargo, no queda claro si este informe tiene carácter preceptivo y vinculante, como ocurre con el informe previsto en el Art. 19 de la Ley

forme sobre la admisibilidad del vertido y, en su caso, determinar las características del mismo y las medidas correctoras a adoptar a fin de preservar el buen estado ecológico de las aguas. En caso de no emitirse este informe en el plazo señalado, el órgano competente para otorgar la autorización ambiental integrada requerirá al organismo de cuenca para que emita con carácter urgente el citado informe en el plazo máximo de un mes, transcurrido el cual se podrán proseguir las actuaciones. No obstante, el informe recibido fuera del plazo señalado y antes del otorgamiento de la autorización ambiental integrada, deberá ser tenido en consideración por el órgano competente de la Comunidad Autónoma. Si el Organismo de cuenca no emite el referido informe, la LPCIC establece que se podrá otorgar la autorización ambiental integrada, contemplando en la misma las características del vertido y las medidas correctoras requeridas, que se establecerán de acuerdo con la legislación de aguas. Ahora bien, en el supuesto de que el informe del Organismo de cuenca considerase que es inadmisible el vertido y consecuentemente, impidiese el otorgamiento de la autorización ambiental integrada, el órgano competente para otorgar la autorización ambiental integrada dictará resolución motivada denegando la autorización. Es la consecuencia lógica del carácter vinculante que se atribuye al citado informe.

94 El contenido de la autorización ambiental integrada, de acuerdo con lo previsto en el Art. 25 de la LGICA, reflejará las condiciones específicas del resto de las autorizaciones que en la misma se integren (entre ellas, lógicamente, las condiciones de vertido). 
16/2002, o simplemente preceptivo. Entendemos que sería preceptivo y vinculante. También prevé el Art. 31.2.d) de la LGICA, que entre la documentación que deba acompañar a la solicitud del titular se incluya la exigida por la normativa aplicable para aquellas autorizaciones que en cada caso se integren en la autorización ambiental unificada, como es el caso de la autorización de vertido.

\subsection{Concurrencia de la autorización de vertido con otras autorizaciones y con- cesiones}

El Art. 85.4 de la LGICA ordena que la autorización de vertido se otorgará sin perjuicio de la concesión que debe exigirse al órgano estatal competente para la ocupación del dominio público marítimo-terrestre de conformidad con lo establecido en la Ley 22/1988, de 28 de julio, de Costas, aunque no establece el carácter previo de la autorización de vertido respecto a aquella concesión.

No es éste el único supuesto de concurrencia de la autorización de vertido con otras autorizaciones o concesiones. Aunque no se mencionan en la Ley, cabe pensar también en la posibilidad de la concurrencia con otras autorizaciones y concesiones para la ocupación o utilización del dominio público hidráulico.

La LGICA sí contempla la posibilidad de que la autorización de vertido concurra con otras autorizaciones de control de la contaminación ambiental (autorización de emisiones a la atmósfera, autorización de producción de residuos, autorización de gestión de residuos) que se requieran para aquellas actuaciones no sometidas a autorización ambiental integrada o autorización ambiental unificada. En este caso, y sin perjuicio de que el procedimiento de resolución de dichas autorizaciones sea el que establezca su normativa específica, la Ley ordena que el periodo de información pública sea común, eso sí, siempre que en la normativa de aplicación a cada una de ellas esté previsto dicho trámite ${ }^{95}$.

\footnotetext{
${ }^{95}$ Art. 47.2 LGICA.
} 


\subsection{El régimen sancionador}

La LGICA completa la regulación de los vertidos con unas previsiones sobre el régimen sancionador ${ }^{96}$. Casi todas las infracciones tipificadas por los Arts. 140 a $142^{97}$ quedan referidas a la acción de verter o están relacionadas con la autorización de vertido. Los grados en que la LGICA clasifica las infracciones y sanciones, a diferencia de lo que ocurre con la Ley de Aguas (que distingue entre leves, menos graves, graves y muy graves), se han adecuado a la trilogía prevista en la Ley 30/1992, distinguiéndose entre infracciones leves, graves y muy graves ${ }^{98}$.

Entre las infracciones muy graves, cuya comisión se sancionará con multa desde 300.506,62 hasta 601.012,10 euros, se tipifican las siguientes actuaciones: a) La realización de vertidos directos o indirectos a cualquier bien del dominio público hidráulico o desde tierra a cualquier bien del dominio público marítimo-terrestre, cualquiera que sea su naturaleza y estado físico, que no cuenten con la correspondiente autorización administrativa, cuando se haya producido un daño o deterioro grave para el medio ambiente ${ }^{99}$ o se haya puesto en peligro grave la salud o seguridad de las personas; b) El incumplimiento de órdenes de suspensión y de medidas correctoras o preventivas dictadas al amparo del artículo 162 de la Ley -que regula las medidas provisionales que pudieron adoptarse al hilo de un procedimiento sancionador-; y c) La superación de los valores límites de emisión recogidos en la autorización de vertido siempre que se haya producido un daño o deterioro grave para el medio ambiente o se haya puesto en peligro grave la seguridad o salud de las personas.

96 Dentro del Título VIII de la Ley sobre "Disciplina ambiental" y del Capítulo III del mismo sobre "Infracciones y Sanciones" se incluye una Sección -la tercera- con la rúbrica "Infracciones y sanciones en materia de calidad del medio hídrico".

${ }^{97}$ No necesariamente "el incumplimiento de las obligaciones establecidas en los programas de actuación para prevenir la contaminación por nitratos de origen agrario y otros contaminantes de origen difuso" (Art. 141.1.c).

98 Sobre el tema puede verse MAGÁN PERALES, J.M. "La jurisprudencia del Tribunal Supremo sobre infracciones y sanciones en materia de aguas", Revista Aranzadi de Derecho Ambiental, $\mathrm{n}^{\circ}$ $8,2005$.

99 En el ámbito estatal, mediante Orden del Ministerio de Medio Ambiente, de 16 enero de 2008, se han establecido los criterios técnicos para la valoración de los daños al dominio público hidráulico y las normas sobre toma de muestras y análisis de vertidos de aguas residuales. 
Como infracciones graves se tipifican las siguientes conductas: a) La realización de vertidos -en los mismos términos previstos para las infracciones muy graves- pero "cuando no se haya producido un daño o deterioro grave para el medio ambiente ni se haya puesto en peligro grave la salud o seguridad de las personas"; b) La superación de los valores límites de emisión establecidos en la autorización de vertido siempre que se superen los valores límites establecidos en la normativa aplicable y no se haya producido un daño o deterioro grave para el medio ambiente; c) El incumplimiento de las obligaciones establecidas en los programas de actuación para prevenir la contaminación por nitratos de origen agrario y otros contaminantes de origen difuso, cuando se haya producido daño o deterioro grave para el medio ambiente; d) El incumplimiento de las condiciones de calidad del medio receptor establecidas en la autorización de vertido; e) La falta de comunicación, a la Consejería competente en materia de medio ambiente, de una situación de emergencia o de peligro derivada de cualquier irregularidad en la emisión de un vertido; f) La dilución sin autorización de los vertidos, con el fin de cumplir los límites establecidos en la autorización de vertido; g) La ocultación de datos o el falseamiento en la documentación a presentar en el procedimiento de autorización de vertido; h) El incumplimiento del plazo fijado en la autorización de vertido para la iniciación o terminación de las obras e instalaciones que soportan el vertido. La comisión de estas infracciones graves se sancionará con multa desde $6.010,13$ hasta $300.506,61$ euros.

Por último, el Art. 142 tipifica y sanciona las infracciones leves, señalando las siguientes: a) El incumplimiento de los valores límites de emisión establecidos en la autorización de vertido sin que se superen los valores límites establecidos en la normativa aplicable; b) El incumplimiento de los planes de mantenimiento y calibración de los equipos de control automático de la calidad de los efluentes impuestos en la autorización de vertido; c) El incumplimiento de la obligación de mantener en buen estado las obras e instalaciones que soportan el vertido; d) El incumplimiento de cualquier otra de las condiciones establecidas en la autorización de vertido; e) El incumplimiento de las obligaciones establecidas en los programas de actuación para prevenir la contaminación por nitratos de origen agrario y otros contaminantes de origen difuso, cuando no se haya producido daño o deterioro para el medio ambiente. La comisión de las infracciones administrativas leves se sanciona con multa de hasta 6.010,12 euros. 